\title{
Goblet Cells in SARS-CoV-2 Pathogenesis
}

\author{
Masfique Mehedi* \\ Department of Biomedical Sciences, University of North Dakota School of Medicine \& Health Sciences, USA
}

*Corresponding author: Masfique Mehedi, Department of Biomedical Sciences, University of North Dakota School of Medicine \& Health Sciences, Grand Forks, ND 58202, USA.

To Cite This Article: Masfique Mehedi, Goblet Cells in SARS-CoV-2 Pathogenesis. 2020 - 11(1). AJBSR.MS.ID.001596.

DOI: 10.34297/AJBSR.2020.11.001596.

Received: 眥 November 28, 2020; Published: 眥 December 02, 2020

\section{SARS-CoV-2 Cell Tropism}

Severe acute respiratory syndrome coronavirus 2 (SARS-CoV-2, a causative agent of coronavirus disease 2019, COVID-19) cellular tropism depends on its receptor-binding specificity. Therefore, the answer for why SARS-CoV-2 is more transmissible than SARS-CoV may find in the expression of the entry receptor angiotensin-converting enzyme II (ACE2) on host cells. SARS-CoV-2 spike protein shows ten times more affinity in binding ACE2 than does SARS-CoV [1]. For successful SARS-CoV-2 entry, spike protein priming is required by a host cell co-factor transmembrane serine protease 2 (TMPRSS2) [2]. Thus, cells with high ACE2 and TMPRSS2 expression are more susceptible to SARS-CoV-2. Previously, RNA-seq based studies suggested that both ACE2 and TMPRSS2 predominately express by the secretory cells in the respiratory system [3-5]. Recent studies suggest that mucus-secreting goblet cells are permissive to SARS-CoV-2 infection [6-8]. Osan et al. [9] have confirmed that the virus preferentially infects goblet cells in the bronchial airway due to harboring higher levels of ACE2 and TMPRSS2 compared to that of ciliated cells. The ability to infect goblet cells may explain the efficient replication and transmission of SARS-CoV-2 as similar to pandemic influenza viruses [10]. Thus, the growing evidence on SARS-CoV-2 infection in goblet cells urges for focusing virus-host tropism studies on goblet cells.

\section{Goblet Cell Hyperplasia}

Goblet cells are the major mucin-producing cell in the superficial epithelium of the large airway [11]. Mucins are large heavily-glycosylated multi-domain protein, which may play a pivotal role in protecting the respiratory tract by entrapping microbes and facilitating removal of them via coordinated beating of motile cilia [12]. The interaction between respiratory pathogens and mucin is far more complicated and understudied. Therefore, SARS-CoV-2 and mucins interaction is an active area of research. Disparities in mucin expression based on gender and age may responsible for different COVID-19 outcomes, such as the higher susceptibility of elderly individuals to SARS-CoV-2 may in part be explained by reduced mucus production and impaired mucociliary clearance [1215]. However, transient mucus hypersecretion is a known phenomenon caused by an increase in goblet cell number in response to the pathogen [16]. Mucus hypersecretion, which is an underlying condition of hypoxia, caused acute respiratory distress syndrome (ARDS) in the SARS-CoV-2 infected patients $[17,18]$. Therefore, goblet cell hyperplasia, a common clinical manifestation in patients with asthma and chronic obstructive pulmonary disease (COPD), could be responsible for severe disease associated with COVID-19 in the chronic disease patients $[16,19,20]$. Indeed, COVID severity and COVID-associated mortality rate are higher in COPD patients compared to patients without COPD [21]. A gene expression-based study has recently suggested that ACE2 expression is significantly higher in bronchial epithelial cells in COPD patients compared to the control subject [22]. Osan et al. [9] have recently shown that SARS-CoV-2 replicates better in the in vitro COPD airway epithelium, which is likely due to COPD-associated goblet cell hyperplasia. Thus, more research needs to determine whether SARS-CoV-2 preferential infection in goblet cells makes patients with chronic lung diseases (such as asthma and COPD) more vulnerable to severe disease outcomes associated with COVID-19.

\section{Multifaceted Goblet Cells}

Goblet cells are not solely mucin-producing cells rather an active regulator of innate and adaptive immune systems. Goblet cells can deliver antigens to the specific dendritic cells in the small intestine [23]. Goblet cells contribute to immunity at mucosal surfaces through several activities: barrier maintenance, goblet cell-associated antigen passage, interaction with antigen-presenting cells, 
and secretion of immunomodulatory factors [24]. However, mucin or goblet cell-based immune regulation is tissue-specific [11] SARS-CoV-2 produces protean manifestations ranging from head to toe, infects multiple organ systems including lung, heart, brain, kidney, and vasculature [25]. It is prudent to determine whether SARS-CoV-2 infection in goblet cells allows the virus to be systemic through the bronchiole similar to the lung alveoli [26].

\section{Treatment Options}

Therapeutic strategies targeting goblet cell differentiation (GCD) may be useful to combat COVID-19 disease exacerbation in chronic disease patients. Corticosteroids are the most commonly prescribed medication for the treatment of asthma, offer a substantial reduction of airway inflammation [27]. A recent study suggested that inhaled corticosteroid attenuates pulmonary expression of SARS-CoV-2 entry receptor ACE2, which may contribute to altered susceptibility to COVID-19 in COPD patients [28]. Corticosteroids such as dexamethasone reduced mortality in COVID-19 hospitalized patients $[29,30]$. The WHO has provided guidelines for corticosteroid use under the COVID-19 drug treatment [31]. However, corticosteroids should be used with caution in patients with COVID-19, as there is a report of increased risk of death and side effects such as bacterial infection and hypokalemia [32]. The author thinks therapeutic drugs targeting viral replication more likely to be effective to combat COVID-19. Encouraging news is that five COVID-19 vaccines are at different stages of large-scale (Phase 3) clinical trials in the USA [33].

\section{Conflict of Interest}

There is no conflict of interest.

\section{References}

1. Wrapp D, Wang N, Corbett KS, Goldsmith JA, Hsieh CL, et al. (2020) CryoEM structure of the 2019-nCoV spike in the prefusion conformation. Science 367(6483): 1260-1263.

2. Hoffmann M, Kleine-Weber H, Schroeder S, Kruger N, Herrler T, et al (2020) SARS-CoV-2 Cell Entry Depends on ACE2 and TMPRSS2 and Is Blocked by a Clinically Proven Protease Inhibitor. Cell 181(2): 271e8$280 \mathrm{e} 8$.

3. Lukassen S, Chua RL, Trefzer T, Kahn NC, Schneider MA, et al. (2020) SARS-CoV-2 receptor ACE2 and TMPRSS2 are primarily expressed in bronchial transient secretory cells. EMBO J 39(10): e105114.

4. Sungnak W, Huang N, Becavin C, Berg M, Queen R, et al. (2020) SARSCoV-2 entry factors are highly expressed in nasal epithelial cells together with innate immune genes. Nat Med 26(5): 681-687.

5. Ziegler CGK, Allon SJ, Nyquist SK, Mbano IM, Miao VN, et al. (2020) SARS-CoV-2 Receptor ACE2 Is an Interferon-Stimulated Gene in Human Airway Epithelial Cells and Is Detected in Specific Cell Subsets across Tissues. Cell 181(5): 1016.e19-1035.e19.

6. Hao S, Ning K, Kuz CA, Vorhies K., Yan Z, et al. (2020) Long-Term Modeling of SARS-CoV-2 Infection of In Vitro Cultured Polarized Human Airway Epithelium. mBio 11(6): e02852-e028520.

7. Hui KPY, Cheung MC, Perera R, Ng KC, Bui CHT, et al. (2020) Tropism, replication competence, and innate immune responses of the coronavirus
SARS-CoV-2 in human respiratory tract and conjunctiva: an analysis in ex-vivo and in-vitro cultures. Lancet Respir Med 8(7): 687-695.

8. Zhu N, Wang W, Liu Z, Liang C, Wang W, et al. (2020) Morphogenesis and cytopathic effect of SARS-CoV-2 infection in human airway epithelial cells. Nat Commun 11(1): 3910.

9. Osan JK, Talukdar SN, Feldmann F, Ann DeMontigny B, Jerome K, et al. (2020). Goblet Cell Hyperplasia Increases SARS-CoV-2 Infection in COPD. bioRxiv 2020.11.11.379099.

10. Matrosovich MN, Matrosovich TY, Gray T, Roberts NA, Klenk HD (2004) Human and avian influenza viruses target different cell types in cultures of human airway epithelium. Proc Natl Acad Sci U S A 101(13): 46204624 .

11. Ma J, Rubin BK, Voynow JA (2018) Mucins, Mucus, and Goblet Cells. Chest 154(1): 169-176.

12. Chatterjee M, van Putten JPM, Strijbis K (2020) Defensive Properties of Mucin Glycoproteins during Respiratory Infections-Relevance for SARSCoV-2. mBio 11(6): e02374-20.

13. Cho SJ, Stout-Delgado HW (2020) Aging and Lung Disease. Annu Rev Physiol 82: 433-459.

14. Harness-Brumley CL, Elliott AC, Rosenbluth DB, Raghavan D, Jain R (2014) Gender differences in outcomes of patients with cystic fibrosis. J Womens Health (Larchmt) 23(12): 1012-1020.

15. Ho JC, Chan KN, Hu WH, Lam WK, Zheng L, et al. (2001) The effect of aging on nasal mucociliary clearance, beat frequency, and ultrastructure of respiratory cilia. Am J Respir Crit Care Med 163(4): 983-988.

16. Shaykhiev R (2019) Emerging biology of persistent mucous cell hyperplasia in COPD. Thorax 74(1): 4-6.

17. Farooqi FI, Morgan RC, Dhawan N, Dinh J, Yatzkan G, et al. (2020) Airway Hygiene in COVID-19 Pneumonia: Treatment Responses of 3 Critically Ill Cruise Ship Employees. Am J Case Rep 21: e926596.

18. Wang C, Xie J, Zhao L, Fei X, Zhang H, et al. (2020) Alveolar macrophage dysfunction and cytokine storm in the pathogenesis of two severe COVID-19 patients. EBioMedicine 57: 102833.

19. Higham A, Mathioudakis A, Vestbo J, Singh D (2020) COVID-19 and COPD: a narrative review of the basic science and clinical outcomes. Eur Respir Rev 29(158): 200199.

20. Rogers DF (2002) Airway goblet cell hyperplasia in asthma: hypersecretory and anti-inflammatory? Clin Exp Allergy 32(8): 11241127.

21. Alqahtani JS, Oyelade T, Aldhahir AM, Alghamdi SM, Almehmadi M, et al. (2020) Prevalence, Severity and Mortality associated with COPD and Smoking in patients with COVID-19: A Rapid Systematic Review and Meta-Analysis. PLoS One 15(5): e0233147.

22. Leung JM, Yang CX, Tam A, Shaipanich T, Hackett TL, et al. (2020) ACE-2 expression in the small airway epithelia of smokers and COPD patients: implications for COVID-19. Eur Respir J 55(5): 2000688.

23. McDole JR, Wheeler LW, McDonald KG, Wang B, Konjufca V, et al. (2012) Goblet cells deliver luminal antigen to CD103+ dendritic cells in the small intestine. Nature 483(7389): 345-349.

24. Knoop KA, Newberry RD (2018) Goblet cells: multifaceted players in immunity at mucosal surfaces. Mucosal Immunol 11(6): 1551-1557.

25. Libby P, Luscher T (2020) COVID-19 is, in the end, an endothelial disease. Eur Heart J 41(32): 3038-3044.

26. Ackermann M, Verleden SE, Kuehnel M, Haverich A, Welte T, et al. (2020). Pulmonary Vascular Endothelialitis, Thrombosis, and Angiogenesis in Covid-19. N Engl J Med 383(2): 120-128. 
27. Reid AT, Veerati PC, Gosens R, Bartlett NW, Wark PA, et al. (2018) Persistent induction of goblet cell differentiation in the airways: Therapeutic approaches. Pharmacol Ther 185: 155-169.

28. Finney LJ, Glanville N, Farne H, Aniscenko J, Fenwick P, et al. (2020) Inhaled corticosteroids downregulate the SARS-CoV-2 receptor ACE2 in COPD through suppression of type I interferon. J Allergy Clin Immunol S0091-6749(20)31407-X.

29. Group RC, Horby P, Lim WS, Emberson JR, Mafham M, et al. (2020) Dexamethasone in Hospitalized Patients with Covid-19 - Preliminary Report. N Engl J Med oa2021436.
30. Matthay MA, Thompson BT (2020) Dexamethasone in hospitalised patients with COVID-19: addressing uncertainties. Lancet Respir Med 8(12): 1170-1172.

31. WHO (2020) Corticosteroids for COVID-19. World Health Organization, Geneva, Switzerland.

32. Yang Z, Liu J, Zhou Y, Zhao X, Zhao Q, et al. (2020) The effect of corticosteroid treatment on patients with coronavirus infection: a systematic review and meta-analysis. J Infect 81(1): e13-e20.

33. CDC (2020) Coronavirus Disease 2019 (COVID-19). 